\title{
Growth requirements and fermentation products of Fusobacterium prausnitzii, and a proposal to reclassify it as Faecalibacterium prausnitzii gen. nov., comb. nov.
}

\footnotetext{
${ }^{1}$ Division of Gut Microbiology and Immunology, Rowett Research Institute, Greenburn Road, Bucksburn, Aberdeen AB21 9SB, UK

2 Department of Medical Microbiology, University of Groningen, Groningen, The Netherlands
}

\author{
Sylvia H. Duncan, ${ }^{1}$ Georgina L. Hold, ${ }^{1}$ Hermie J. M. Harmsen, ${ }^{2}$ \\ Colin S. Stewart ${ }^{1}$ and Harry J. Flint ${ }^{1}$
}

\begin{abstract}
Author for correspondence: Sylvia H. Duncan. Tel: +44 1224 712751. Fax: +44 1224716687. e-mail: shd@rri.sari.ac.uk
\end{abstract}

\begin{abstract}
Two newly isolated strains of obligately anaerobic bacteria from human faeces are shown here to be related to Fusobacterium prausnitzii, which is regarded as one of the most abundant colonizers of the human colon. These strains, along with Fusobacterium prausnitzii ATCC $27768^{\top}$ and 27766 , are non-motile and produce butyrate, formate and lactate, but not hydrogen as fermentation products. A new finding is that all four strains produce D-lactate, but not Llactate. The strains have a requirement for acetate in the growth medium and this may account for the previously reported requirement for rumen fluid. The DNA G+C content of the four strains is $47-57 \mathrm{~mol} \%$. Together with phylogenetic analysis based on 16S rRNA sequencing, this establishes that Fusobacterium prausnitzii strains are only distantly related to Fusobacterium sensu stricto and are more closely related to members of Clostridium cluster IV (the Clostridium leptum group). It is proposed that a new genus, Faecalibacterium gen. nov. be created; this genus should include Faecalibacterium prausnitzii gen. nov., comb. nov. ATCC $27768^{\top}$ ( = NCIMB $13872^{\top}$ ) (formerly Fusobacterium prausnitzii) as the type species together with ATCC 27766 and the newly isolated strains A2-165 and L2-6.
\end{abstract} Keywords: Faecalibacterium prausnitzii, Fusobacterium, human faeces, butyrate, D-
lactate

\section{INTRODUCTION}

Bacteria currently classified as Fusobacterium prauznitzii are recognized as being among the most abundant representatives of the human faecal flora (Cato et al., 1974; Holdeman et al., 1976; Moore \& Moore, 1995). Their abundance has been further confirmed by recent evidence from 16S rRNA analyses of bacterial diversity in human faeces and colon samples that are independent of cultivation (Wilson \& Blitchington, 1996; Wang et al., 1996a; Suau et al., 1999, 2001; Franks et al., 1998; Hold et al., 2002). In addition, bacteria related to Fusobacterium prausnitzii

Abbreviation: SCFA, short-chain fatty acid(s).

The GenBank accession numbers for the 16S rRNA gene sequences of Fusobacterium prausnitzii ATCC $27768^{\top}$ and from the new isolates L2-6 and A2-165 are AJ413954, AJ270469 and AJ270470, respectively. accounted for a significant proportion of randomly isolated anaerobes from human faeces that produce major quantities of butyrate (Barcenilla et al., 2000).

Strains classified phenotypically as Fusobacterium prausnitzii are not phylogenetically related to true Fusobacterium species, based on the 16S rDNA sequence of Fusobacterium prausnitzii ATCC 27766 (Wang et al., 1996a). True representatives of the genus Fusobacterium are Gram-negative, non-spore-forming anaerobic rods that show a DNA $\mathrm{G}+\mathrm{C}$ content between 26 and $34 \mathrm{~mol} \%$ (Hauduroy et al., 1937; Cato et al., 1974; Moore et al., 1984). Based on 16S rRNA sequencing, typical species (including Fusobacterium nucleatum and Fusobacterium necrophorum) form a distinct cluster in the eubacterial phylogenetic tree. In marked contrast, Fusobacterium prausnitzii strains show a DNA G $+\mathrm{C}$ content between 47 and $57 \mathrm{~mol} \%$ and their 16S rRNA sequences indicate relatedness 
with Gram-positive bacteria of the Clostridium leptum group (Franks et al., 1998; Suau et al., 2001).

Here we examine the characteristics and growth requirements of two newly isolated Fusobacterium prausnitzii strains from human faeces and propose that these strains, along with Fusobacterium prausnitzii ATCC $27768^{\mathrm{T}}\left(=\right.$ NCIMB $\left.13872^{\mathrm{T}}\right)$ and ATCC 27766 , should be placed in the new genus Faecalibacterium.

\section{METHODS}

Bacterial strains and growth conditions. Two strains (A2-165 and L2-6) were isolated from the highest countable dilution of human faecal samples in roll tubes (Hungate, 1966) of anaerobic M2GSC medium (Miyazaki et al., 1997), as described by Barcenilla et al. (2000). Anaerobic culture methods were those of Bryant (1972) using Hungate culture tubes, sealed with butyl rubber septa (Bellco Glass). Media were prepared and maintained anaerobically using $\mathrm{O}_{2}$-free $\mathrm{CO}_{2}$. The isolates were routinely maintained by growing for $16-18 \mathrm{~h}$ at $37^{\circ} \mathrm{C}$ in $7.5 \mathrm{ml}$ aliquots of M2GSC medium.

Morphology. The cellular morphology of the new isolates was determined by Gram staining exponential- and stationary-phase cultures as described by Holdeman et al. (1977). Sixteen-hour-old cultures were examined by phasecontrast microscopy for motility and observed by scanning electron microscopy for the presence of flagella, following the procedure described by Stewart et al. (1990).

Substrate utilization and hydrolysis. Substrate utilization was determined by adding a final concentration of $0.5 \%$ stock filter-sterilized sugar solutions $(10 \%, \mathrm{w} / \mathrm{v})$ to YCFA medium dispensed in $7.5 \mathrm{ml}$ aliquots in Hungate tubes. YCFA medium consisted of (per $100 \mathrm{ml}$ ): $1 \mathrm{~g}$ casitone, $0.25 \mathrm{~g}$ yeast extract, $0.4 \mathrm{~g} \mathrm{NaHCO}, 0.1 \mathrm{~g}$ cysteine, $0.045 \mathrm{~g}$ $\mathrm{K}_{2} \mathrm{HPO}_{4}, \quad 0.045 \mathrm{~g} \quad \mathrm{KH}_{2} \mathrm{PO}_{4}, \quad 0.09 \mathrm{~g} \quad \mathrm{NaCl}, \quad 0.009 \mathrm{~g}$ $\mathrm{MgSO}_{4} .7 \mathrm{H}_{2} \mathrm{O}, 0.009 \mathrm{~g} \mathrm{CaCl}, 0.1 \mathrm{mg}$ resazurin, $1 \mathrm{mg}$ haemin, $1 \mu \mathrm{g}$ biotin, $1 \mu \mathrm{g}$ cobalamin, $3 \mu \mathrm{g} p$-aminobenzoic acid, $5 \mu \mathrm{g}$ folic acid and $15 \mu \mathrm{g}$ pyridoxamine. Final concentrations of short-chain fatty acids (SCFA) in the medium were $33 \mathrm{mM}$ acetate, $9 \mathrm{mM}$ propionate and $1 \mathrm{mM}$ each of isobutyrate, isovalerate and valerate. All components were added aseptically while the tubes were flushed with $\mathrm{CO}_{2}$. Heat labile vitamins were added after the medium was autoclaved to give a final concentration of $0.05 \mu \mathrm{g}$ thiamine $\mathrm{ml}^{-1}$ and $0.05 \mu \mathrm{g}$ riboflavin $\mathrm{ml}^{-1}$. YCFA supplemented with $25 \mathrm{mM}$ glucose (YCFAG) provided a convenient alternative to rumen fluid medium for the cultivation of the strains in this study. Growth was measured spectrophotometrically as $\mathrm{OD}_{650}$. Twelve different arylamidase activities were tested using API rapid ID-32A test kits (bioMérieux). The activities tested were arginine arylamide, proline arylamide, leucineglycine arylamide, phenylalanine arylamide, leucine arylamide, pyroglutamic acid arylamide, tyrosine arylamide, alanine arylamide, glycine arylamide, histidine arylamide, serine arylamide and glutamyl glutamic acid arylamide. Aesculin hydrolysis was determined as described by Duncan et al. (1998).

Fermentation product analysis. Acid production was determined by capillary GC (Richardson et al., 1989) and the gaseous products were analysed by packed-column GC (Rumney et al., 1995).

DNA preparation and DNA base composition. DNA was extracted from 24-h-old cultures grown on M2GSC medium following the method of Ausubel et al. (1994). Chromosomal DNA was purified by standard methods (Sambrook et al., 1989) and the $G+C$ content was determined using the thermal denaturation procedure as described by Johnson (1981).

$16 S$ rDNA sequencing and phylogenetic analysis. For amplification of $16 \mathrm{~S}$ rDNA, a universal primer set, corresponding to positions 8-27 (forward primer) and 1492-1510 (reverse primer) of the Escherichia coli numbering system was used (Weisberg et al., 1991). The PCR conditions were as described by Wood et al. (1998). Direct sequencing of the amplified DNA fragments was performed using an automated ABI 377 sequencer as described previously (Hold et al., 2001). Similarity of the $16 \mathrm{~S}$ rRNA sequences was compared with all sequence data in GenBank and EMBL using the BLAST algorithm (Altschul et al., 1990) and the Ribosomal Database Project (Maidak et al., 2001). Nucleotide sequences were aligned using the PILEUP program (Devereux et al., 1984). The resulting multiple sequence alignment was corrected manually, with approximately $1340 \mathrm{nt}$ being used in the subsequent phylogenetic analysis which corresponded to positions 60-1400 within the 16S rRNA gene (based on E. coli numbering). The phylogenetic tree was constructed using the neighbour-joining method (Saitou \& Nei, 1987), via the PHYLIP package (Felsenstein, 1989) using DNADIST for distance analysis (Kimura, 1980). The stability of the groupings was estimated by bootstrap analysis (500 replications) using the programs of the PHYLIP package (Felsenstein, 1989).

\section{RESULTS}

\section{Molecular characterization and phylogenetic relationships}

The $16 \mathrm{~S}$ rRNA sequences of the two recently isolated strains, A2-165 and L2-6, were determined and found to be $96 \%$ identical to that of Fusobacterium prausnitzii strain ATCC 27766 as sequenced by Wang et al. (1996a) and $97 \%$ identical to the $16 \mathrm{~S}$ rRNA sequence of Fusobacterium prausnitzii ATCC $27768^{\mathrm{T}}$ obtained during the current investigation (Fig. 1). Comparison of the 16S rRNA gene sequences from Fusobacterium prausnitzii with the 16S rRNA gene sequence from the Fusobacterium type species, Fusobacterium nucleatum ATCC $25586^{\mathrm{T}}$, showed that they possessed $<77 \%$ sequence identity. The $\mathrm{G}+\mathrm{C}$ content was determined for strains A2-165, L2-6 and ATCC 27766, with all strains giving values between 47 and 49 mol \% (Table 1). This is in contrast to $\mathrm{G}+\mathrm{C}$ content of other Fusobacterium strains which have been reported to have values between 26 and $34 \mathrm{~mol} \%$ (Moore et al., 1984).

\section{Cell morphology}

The new strains isolated from human faeces were Gram-negative rods measuring approximately $0.5 \times 0.8-2.0 \times 9.0 \mu \mathrm{m}$ and similar data were also obtained from existing strains (Table 1). All four isolates were shown to be non-motile and a scanning electron micrograph of the non-flagellated strain A2165 is shown in Fig. 2. 


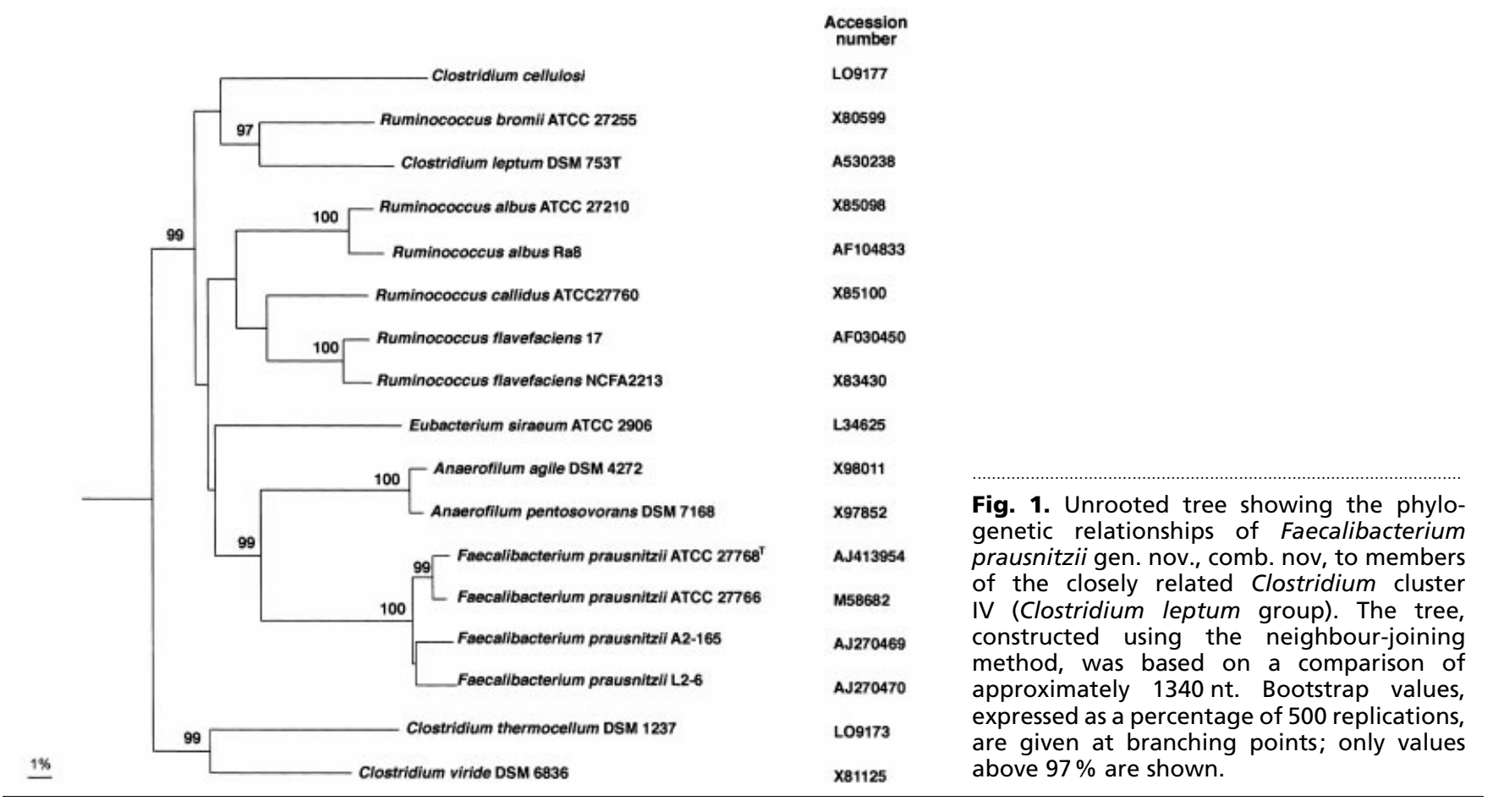

Table 1. Phenotypic properties of Faecalibacterium prausnitzii strains

Growth was determined by measuring $\mathrm{OD}_{650}$ in YCFA medium supplemented with the appropriate substrate $(0 \cdot 5 \%$, w/v, final concn; see Methods). All strains were non-motile, Gram-negative rods. All strains grew on fructose, fructo-oligosaccharides and glucose, but failed to grow on arabinose, melibiose, raffinose, rhamnose, ribose and xylose. All strains possessed $\beta$-galactosidase, $\alpha$-glucosidase and phosphatase activities in API 32A tests, but did not possess urease, arginine dihydrolase, $\beta$-glucosidase and $\alpha$-fucosidase activities. None of the strains reduced nitrate or produced indole. All strains utilized acetate, but did not produce $\mathrm{H}_{2}$. The products of fermentation from all four strains were formate, butyrate, D-lactate and $\mathrm{CO}_{2}$. W, Weak reaction; NA, data not available.

\begin{tabular}{|c|c|c|c|c|}
\hline Isolate & A2-165 & L2-6 & F. prausnitzii АТСС 27766 & F. prausnitzii ATCC $27768^{\mathrm{T}} *$ \\
\hline Size $(\mu \mathrm{m})$ & $0 \cdot 5-0.8 \times 2 \cdot 0-9 \cdot 0$ & $0.5-0.8 \times 2 \cdot 0-9 \cdot 0$ & $0.5-0.8 \times 2 \cdot 0-9 \cdot 0$ & $0 \cdot 5-0 \cdot 9 \times 2 \cdot 5-14$ \\
\hline $\mathrm{DNA} G+\mathrm{C}(\mathrm{mol} \%)$ & 49 & 47 & 47 & $52-57$ \\
\hline \multicolumn{5}{|l|}{ Growth on: } \\
\hline Cellobiose & + & - & - & w \\
\hline Maltose & + & + & - & w \\
\hline Mannitol & - & - & - & NA \\
\hline Melezitose & - & - & + & - \\
\hline Sucrose & - & $\mathrm{w}$ & - & w \\
\hline Trehalose & - & - & - & w \\
\hline Starch solution & + & + & + & $\mathrm{w}$ \\
\hline Inulin & + & $\mathrm{w}$ & + & + \\
\hline Hydrolysis of aesculin & W & + & + & + \\
\hline$\alpha$-Galactosidase activity $\dagger$ & $\mathrm{w}$ & - & - & w \\
\hline
\end{tabular}

* Description as for Fusobacterium prausnitzii (Moore et al., 1984).

$\uparrow$ Determined by an API 32A test kit.

\section{Substrates fermented}

Phenotypic characteristics of the four strains are shown in Table 1. All strains possessed the ability to hydrolyse fructose, fructo-oligosaccharide, starch and inulin. None of the strains utilized arabinose, melibiose, raffinose, rhamnose, ribose and xylose. All strains were net acetate utilizers (Table 2) and produced carbon dioxide, but none produced hydrogen. The four strains differed in their ability to ferment cellobiose, maltose and melezitose. 


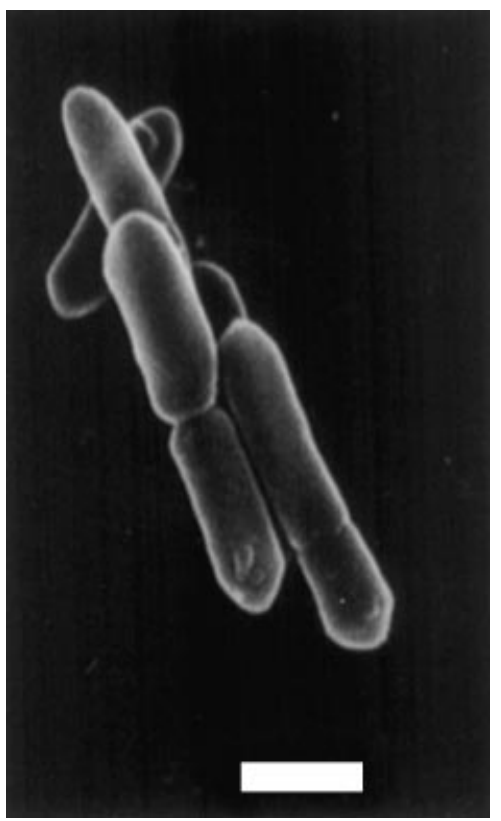

Fig. 2. Scanning electron micrograph of F. prausnitzii strain A2165. Bar, $1 \mu \mathrm{m}$.

All strains hydrolysed the arginine and histidine arylamide substrates, but failed to hydrolyse the proline, leucine-glycine, phenylalanine, leucine, tyrosine, alanine, serine, pyroglutamic acid, glutamyl glutamic acid and glycine, with the exception of strains A2-165 and L2-6 that possessed weak glycine arylamidase activity, when tested using an API 32A test kit.

\section{Fermentation products, growth requirements and tolerance of air}

The major end products of glucose fermentation by the Fusobacterium prausnitzii strains were formate, butyrate and D-lactate (Table 2), with L-lactate being undetectable for all four strains. Although first isolated on M2GSC (30\% rumen fluid) medium, A2-165 and L2-6 were able to grow on simplified medium containing SCFA (YCFA medium), but showed strong growth stimulation by $33 \mathrm{mM}$ acetate (Table 3). Indeed strains ATCC 27766 and L2-6 failed to grow in the absence of added acetate. No growth of strain A2165 was detected when yeast extract was omitted from YCFAG medium (data not shown).

Experiments aimed at identifying the susceptibility of A2-165 to air indicated that Fusobacterium prausnitzii A2-165 could be cultivated on pre-reduced $1.5 \%$ agar plates contained in an anaerobic glove box, rather than using the Hungate technique. However, exposure of inoculated plates to air for more than 2 min was sufficient to prevent subsequent anaerobic growth. Fusobacterium nucleatum ATCC $25586^{\mathrm{T}}$ on the other hand is reported to grow in the presence of $6 \%$ oxygen and survives exposure to air for 100 min (Loesche, 1969).

\section{DISCUSSION}

It is important that the phylogenetic position of this major species of human colonic anaerobe is now clarified to avoid confusion with the unrelated Fuso-

Table 2. Fermentation products formed by Faecalibacterium prausnitzii isolates on the rumen fluid containing M2G medium ( $25 \mathrm{mM}$ glucose final concentration)

Concentrations $(\mathrm{mM})$ are the means of three values $\pm \mathrm{SD}$.

\begin{tabular}{|lrrrr|}
\hline Isolate & \multicolumn{1}{c}{ Formate } & \multicolumn{1}{c}{ Acetate } & Butyrate & D-Lactate \\
\hline A2-165 & $17 \cdot 30 \pm 3 \cdot 51$ & $-5 \cdot 31 \pm 2 \cdot 71$ & $13 \cdot 79 \pm 1 \cdot 75$ & $1 \cdot 70 \pm 0 \cdot 27$ \\
L2-6 & $7 \cdot 65 \pm 1 \cdot 30$ & $-12 \cdot 29 \pm 1 \cdot 83$ & $18 \cdot 64 \pm 1 \cdot 15$ & $5 \cdot 33 \pm 0 \cdot 19$ \\
ATCC 27766 & $4 \cdot 68 \pm 0 \cdot 67$ & $-10 \cdot 25 \pm 1 \cdot 33$ & $13 \cdot 18 \pm 0 \cdot 67$ & $2 \cdot 56 \pm 0 \cdot 31$ \\
ATCC 27768 & $10 \cdot 25 \pm 0 \cdot 72$ & $-9 \cdot 72 \pm 2 \cdot 10$ & $18 \cdot 56 \pm 1 \cdot 57$ & $5 \cdot 47 \pm 0 \cdot 83$ \\
\hline
\end{tabular}

Table 3. Effects of SCFA on growth rates of Faecalibacterium prausnitzii isolates on YCFA medium

\begin{tabular}{|c|c|c|c|c|c|c|}
\hline \multirow[t]{2}{*}{ Isolate } & \multicolumn{2}{|c|}{+ SCFA $^{*}$} & \multicolumn{2}{|c|}{-SCFA } & \multicolumn{2}{|c|}{$-\mathrm{SCFA}+33 \mathrm{mM}$ acetate } \\
\hline & Max. OD 650 & $\mu\left(\mathrm{h}^{-1}\right) \dagger$ & Max. OD $_{650}$ & $\mu\left(\mathrm{h}^{-1}\right) \dagger$ & Max. OD 650 & $\mu\left(\mathrm{h}^{-1}\right) \dagger$ \\
\hline A2-165 & $0.97 \pm 0.03$ & $0 \cdot 21 \pm 0 \cdot 03$ & $0 \cdot 25 \pm 0 \cdot 05$ & $0 \cdot 10 \pm 0 \cdot 01$ & $0 \cdot 90 \pm 0 \cdot 00$ & $0 \cdot 32 \pm 0 \cdot 04$ \\
\hline L2-6 & $0 \cdot 39 \pm 0 \cdot 10$ & $0 \cdot 15 \pm 0 \cdot 01$ & $0 \cdot 10 \pm 0 \cdot 05$ & ND & $0 \cdot 39 \pm 0 \cdot 11$ & $0 \cdot 38 \pm 0 \cdot 06$ \\
\hline ATCC 27766 & $0 \cdot 19 \pm 0 \cdot 01$ & $0 \cdot 11 \pm 0 \cdot 014$ & $0 \cdot 04 \pm 0 \cdot 01$ & ND & $0 \cdot 22 \pm 0 \cdot 02$ & $0 \cdot 10 \pm 0 \cdot 01$ \\
\hline
\end{tabular}

* SCFA final concentrations in the medium were $33 \mathrm{mM}$ acetate, $9 \mathrm{mM}$ propionate and $1 \mathrm{mM}$ each of isobutyrate, isovalerate and valerate.

$\uparrow$ Growth rates $(\mu)$ are the means of three replicate values \pm SD. ND, Growth rates not determined as increase in absorbance was $\leqslant 0 \cdot 1$. 
bacterium spp. through the designation of the new genus Faecalibacterium. There is only $77 \% 16 \mathrm{~S}$ rDNA sequence identity between Fusobacterium prausnitzii and the Fusobacterium type species Fusobacterium nucleatum ATCC $25586^{\mathrm{T}}$. Furthermore, the $\mathrm{G}+\mathrm{C}$ content of Fusobacterium prausnitzii is $47-57 \mathrm{~mol} \%$ compared to 26-34 mol \% for true Fusobacterium spp., clearly indicating that they are unrelated. Phenotypic characteristics also show that all of the 10 Fusobacterium spp. that have been described produced acetate as a fermentation product (Moore et al., 1984) with the exception of Fusobacterium prausnitzii which, as confirmed here, is a net acetate utilizer. In addition, Fusobacterium prausnitzii is particularly sensitive to exposure to air, surviving for less than $2 \mathrm{~min}$, while Fusobacterium nucleatum is reported to be relatively tolerant, retaining viability for nearly $2 \mathrm{~h}$ (Loesche, 1969).

The creation of the proposed new genus, Faecalibacterium, will help to facilitate future research involving its ecology and physiology in the human colonic ecosystem. The present analyses indicate that Faecalibacterium (formerly Fusobacterium) prausnitzii may make a significant contribution to D-lactate and butyrate formation in the large intestine. The production of butyrate is potentially significant because of the role that butyrate plays as an energy source for the colonic epithelium (Roediger, 1980; Scheppach et al., 1998) and in the prevention of colitis and colorectal cancer (Roediger, 1980; Tran et al., 1998). In contrast, the production of D-lactate may also be highly significant in view of the potentially toxic effects of D-lactate accumulation in the bloodstream (Lalive et al., 2001) as few of the predominant anaerobic bacteria inhabiting the gut have been identified as D-lactate producers.

\section{Description of Faecalibacterium gen. nov.}

Faecalibacterium (Fae.ca.li.bac.te'ri.um. L. adj. faecalis pertaining to faeces; Gr. dim. n. bakterion a small rod; N.L. neut. n. Faecalibacterium rod from faeces, as this bacterium is present in high numbers in faeces in the colon, its presumed habitat).

Gram-negative, non-spore-forming and strictly anaerobic. The non-motile organism produces butyrate, D-lactate and formate, and utilizes acetate. Genomic DNA G + C content is $47-57 \mathrm{~mol} \%$ (as determined by thermal denaturation). The type strain, whose characteristics were reported by Cato et al. (1974), is Faecalibacterium prausnitzii ATCC $27768^{\mathrm{T}} \quad(=$ NCIMB $13872^{\mathrm{T}}$ ).

\section{Transfer of Fusobacterium prausnitzii to the genus Faecalibacterium gen. nov. as Faecalibacterium prausnitzii gen. nov., comb. nov.}

Physiological, phenotypic and phylogenetic data indicate that Fusobacterium prausnitzii is not closely related to the type species of the genus Fusobacterium within which it is currently held. It is clearly placed within Clostridium cluster IV (described by Collins et al., 1994), although with sufficient distance to merit the creation of a new genus. The original description of the species given by Moore et al. (1984) is unchanged.

\section{ACKNOWLEDGEMENTS}

We thank Adela Barcenilla, Virgile Duclos, Alan Ramsay and Kenneth Young for their help. R. R. I. receives financial support from the Scottish Executive Environment and Rural Affairs Department (SEERAD).

\section{REFERENCES}

Altschul, S. F., Gish, W., Miller, W., Myers, E. W. \& Lipman, D. J. (1990). Basic local alignment search tool. J Mol Biol 215, 403-410.

Ausubel, F. M., Brent, R., Kingston, R. E., Moore, D. M., Seidman, J. G., Smith, J. A. \& Struhl, K. (1994). Current Protocols in Molecular Biology, vol. 1. New York: Wiley.

Barcenilla, A., Pryde, S. E., Martin, J. C., Duncan, S. H., Stewart, C. S. \& Flint, H. J. (2000). Phylogenetic relationships of butyrateproducing bacteria from the human gut. Appl Environ Microbiol 66, 1654-1661.

Bryant, M. P. (1972). Commentary on the Hungate technique for cultivation of anaerobic bacteria. Am J Clin Nutr 25, 1324-1328.

Cato, E. P., Salmon, C. W. \& Moore, W. E. C. (1974). Fusobacterium prausnitzii (Hauduroy et al.) Moore and Holdeman: emended description and designation of neotype strain. Int J Syst Bacteriol 24, 225-229.

Collins, M. D., Lawson, P. A., Willems, A., Cordoba, J. J., Fernandez-Garayzabal, J., Garcia, P., Cai, J., Hippe, H. \& Farrow, J. A. E. (1994). The phylogeny of the genus Clostridium: proposal for five new genera and eleven new species combinations. Int $J$ Syst Bacteriol 44, 812-826.

Devereux, J., Haeberli, P. \& Smithies, O. (1984). A comprehensive set of sequence analysis programs for the VAX. Nucleic Acids Res 12, 387-395.

Duncan, S. H., Flint, H. J. \& Stewart, C. S. (1998). Inhibitory activity of gut bacteria against E. coli $\mathrm{O} 157$ mediated by dietary plant metabolites. FEMS Microbiol Lett 164, 283-288.

Franks, A. H., Harmsen, H. J. M., Raangs, G. C., Jansen, G. J. \& Welling, G. W. (1998). Variations of bacterial populations in human feces quantified by fluorescent in situ hybridisation with group-specific 16S rRNA-targeted probes. Appl Environ Microbiol 64, 3336-3345.

Felsenstein, J. (1989). PHYLIP-phylogeny inference package (version 3.2). Cladistics 5, 164-166.

Hauduroy, P., Ehringer, A., Guillot, G. \& Magrou, J. (1937). Dictionnaire des Bactéries Pathogènes. Paris: Masson.

Hold, G. L., Smith, E. A., Rappé, M. \& 7 other authors (2001). Characterisation of bacterial communities associated with toxic and non-toxic dinoflagellates: Alexandrium spp. and Scrippsiella trochoidea. FEMS Microbiol Ecol 37, 161-173.

Hold, G. L., Pryde, S. E., Russell, V. J., Furrie, E. \& Flint, H. J. (2002). Assessment of microbial diversity in human colonic samples by $16 \mathrm{~S}$ rDNA sequence analysis. FEMS Microbiol Ecol 39, 33-39.

Holdeman, L. V., Good, I. J. \& Moore, W. E. C. (1976). Human fecal flora: variation in the bacterial composition within individuals and a possible effect of emotional stress. Appl Environ Microbiol 31, 359-375. Holdeman, L. V., Cato, E. P. \& Moore, W. E. C. (1977). Anaerobe Laboratory Manual, 4th edn. Blacksburg, VA: Virginia Polytechnic Institute and State University.

Hungate, R. E. (1966). The Rumen and its Anaerobes. New York, London: Academic Press.

Johnson, J. L. (1981). Genetic characterisation. In Manual of Methods for General Bacteriology, pp. 450-472. Edited by P. Gerdhart \& others. Washington, DC: American Society for Microbiology. 
Kimura, M. (1980). A simple method for estimating evolutionary rates of base substitutions through comparative studies of nucleotide sequences. Mol Evol 16, 111-120.

Lalive, P. H., Hadengue, A., Mensi, N. \& Burkhard, P. R. (2001). Recurrent encephalopathy after small bowel resection. Implication of D-lactate. Rev Neurol 157, 679-681.

Loesche, W. J. (1969). Oxygen sensitivity of various anaerobic bacteria. Appl Microbiol 18, 723-727.

Maidak, B. L., Cole, J. R., Lilburn, T. G. \& 7 other authors (2001). RDP-II (Ribosomal Database project). Nucleic Acids Res 29, 173-174.

Miyazaki, K., Martin, J. C., Marinsek-Logar, R. \& Flint, H. J. (1997). Degradation and utilisation of xylans by the rumen anaerobe Prevotella bryantii (formerly P. ruminicola subsp. brevis) $\mathrm{B}_{1} 4$. Anaerobe 3, 373-381.

Moore, W. E. C. \& Moore, L. H. (1995). Intestinal floras of populations that have a high risk of colon cancer. Appl Environ Microbiol 61, 3202-3207.

Moore, W. E. C., Holdeman, L. V. \& Kelley, R. W. (1984). Genus Fusobacterium Knorr 1922, 4 ${ }^{\mathrm{AL}}$. In Bergey's Manual of Systematic Bacteriology, vol. 1, pp. 631-637. Edited by N. R. Krieg \& J. G. Holt. Baltimore: Williams \& Wilkins.

Richardson, A. J., Calder, A. G., Stewart, C. S. \& Smith, A. (1989). Simultaneous determination of volatile and non-volatile acidic fermentation products of anaerobes by capillary gas chromatography. Lett Appl Microbiol 9, 5-8.

Roediger, W. E. W. (1980). The colonic epithelium in ulcerative colitis : an energy deficient disease? Lancet ii, 712-715.

Rumney, C., Duncan, S. H., Henderson, C. \& Stewart, C. S. (1995). Isolation and characteristics of a wheatbran degrading Butyrivibrio from human faeces. Lett Appl Microbiol 20, 232-236.

Sambrook, J., Fritsch, E. F. \& Maniatis, T. (1989). Molecular Cloning a Laboratory Manual, 2nd edn. Cold Spring Harbor, NY: Cold Spring Harbor Laboratory.
Saitou, N. \& Nei, M. (1987). The neighbor-joining method: a new method for reconstructing phylogenetic trees, Mol Biol Evol 4, 406-425. Scheppach, W., Bartram, H. P. \& Richter, F. (1998). Role of shortchain fatty acids in the prevention of colorectal cancer. Eur J Cancer 31A, 1077-1080

Stewart, C. S., Duncan, S. H. \& Flint, H. J. (1990). The properties of forms of Ruminococcus flavefaciens which differ in their ability to degrade cotton cellulose. FEMS Microbiol Lett 72, 47-50.

Suau, A., Bonnet, R., Sutren, M., Gordon, J. J., Gibson, G. R., Collins, M. D. \& Dore, J. (1999). Direct analysis of genes encoding $16 \mathrm{~S}$ rRNA from complex communities reveals many novel molecular species within the human gut. Appl Environ Microbiol 65, 4799-4807.

Suau, A., Rochet, V., Sghir, A., Gramet, G., Brewaeys, S., Sutren, M., Rigottier-Gois, L. \& Dore, J. (2001). Fusobacterium prausnitzii and related species represent a dominant group within the human fecal flora. Syst Appl Microbiol 24, 139-145.

Tran, C. P., Familari, M., Parker, L. M., Whitehead, R. H. \& Giraud, A. S. (1998). Short-chain fatty acids inhibit intestinal trefoil factor gene expression in colon cancer cells. Am J Physiol-Gastrointest Liver Physiol 38, G85-G93.

Wang, R. F., Cao, W. \& Cerniglia, C. E. (1996a). Phylogenetic analysis of Fusobacterium prausnitzii based on the 16S rRNA gene sequence and PCR confirmation. Int J Syst Bacteriol 46, 341-343.

Weisburg, W. G., Barns, S. M., Pelletier, D. A. \& Lane, D. J. (1991). 16S ribosomal DNA for phylogenetic study. J Bacteriol 173, 697-703.

Wilson, K. H. \& Blitchington, R. B. (1996). Human colonic biota studied by ribosomal DNA sequence analysis. Appl Environ Microbiol 62, 2273-2278.

Wood, J., Scott, K. P., Avgustin, G., Newbold, C. J. \& Flint, H. J. (1998). Estimation of the relative abundance of different Prevotella ribotypes in gut samples by restriction enzyme profiling of PCRamplified 16S rRNA gene sequences. Appl Environ Microbiol 64, 3683-3689. 